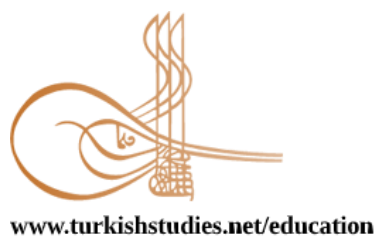

www.turkishstudies.net/education
Turkish Studies - Educational Sciences

eISSN: 2667-5609

Research Article / Araștırma Makalesi

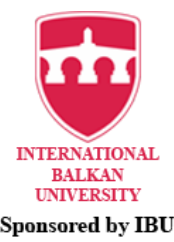

Sponsored by IBU

\title{
Sınıf Öğretmenlerinin Müzik Eğitimine Yönelik Öz-Yeterlikleri: Bir Ölçek Uyarlama Çalışması
}

\author{
Self-Efficacy of Classroom Teachers Towards Music Education: A Scale Adaptation Study
}

\author{
Merve Nur Kale* - Gülnihal Gül ${ }^{* *}$
}

\begin{abstract}
In music education carried out special purposes such as developing the individual's musical perception-knowledge, aesthetic thought, creativity, ability, individual, social relations, mental skills and etc., it has been considered important for the classroom teacher to have sufficient knowledge of the music field and to use this field knowledge in the education process. For this reason, the high level of self-efficacy beliefs towards music education of classroom teachers who are working in primary school level, one of the important steps of basic education, will contribute to the effective and productive education and to educate equipped individuals. Music education activities contribute not only to the academic success of children, but also to the development of identity, friendship and social communication. Therefore, it has been considered important for the child to benefit from music education that can maximize his/her interests, needs and capacities in the primary school period, and it has been thought that the classroom teacher's being equipped in the field of music education and having high self-efficacy level will support and shape the child's musical development process. In respect to this, the study aimed to present the adaptation and validity-reliability studies of the "Problem Determination Scale for Physical Education and Sports Course" developed by Bozdemir (2012) to the determination the self-efficacy of the classroom teachers towards the music lesson. The research was carried out with 252 classroom teachers working in primary schools with the permission of The Provincial Director of National Education, numbered 5445474, dated 14 March 2019, in Usak, Turkey. As a result of the validity and reliability studies with 5-point Likert-type scale, it was determined that the scale has been adapted to the selfefficacy scale for music lessons and consisted of 20 items distributed across 5 factors. Kaiser-Meyer-Olkin sample suitability test for determining whether the data obtained from the application of the scale is suitable for factor analysis and Factor Analysis for determining the factor structure of the scale were performed. Cronbach Alpha coefficient was also determined to test its validity and was calculated as 0.743 . As a result of the principal components analysis which was applied to be able to analyze the dataset with factor analysis, 5 factors with an eigenvalue of 1 and above were formed. According to the results obtained, it can be said that the scale adapted to measure the self-efficacy of classroom teachers for music education is an appropriate measurement tool.
\end{abstract}

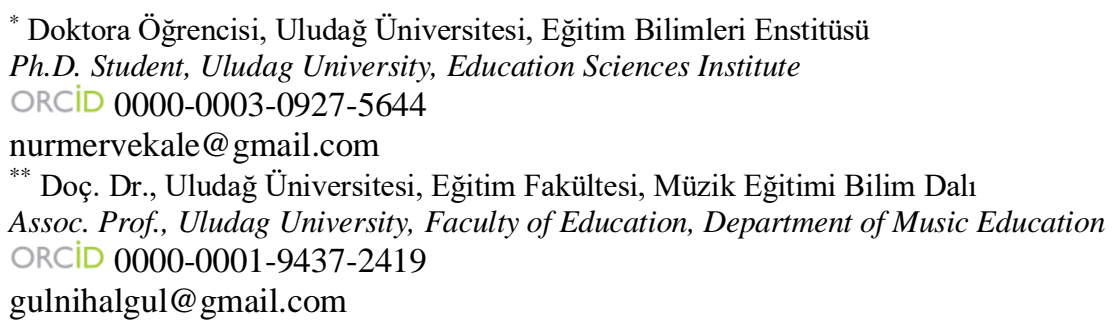

Cite as/ Atıf: Kale, M. N. \& Gül, G. (2020). Sınıf öğretmenlerinin müzik eğitimine yönelik öz-yeterlikleri: bir ölçek uyarlama çalışması. Turkish Studies - Education, 15(4), 2709-2720. https://dx.doi.org/10.47423/TurkishStudies.42700

Received/Geliş: 16 May/Mayıs 2020

Accepted/Kabul: 27 August/Ağustos 2020

Copyright (C INTAC LTD, Turkey
Checked by plagiarism software

Published/Yayın: 30 August/Ağustos 2020

CC BY-NC 4.0 
Structured Abstract: Introduction: Education process, which has important contribution to the development of the personality and to the achievement of the knowledge, skills and understanding necessary for the individual to take his place in social life, starts into family. Institutionally, it starts in the preschool period and continues in the compulsory education period. In this context, teacher's equipment and his/her ability to create an effective-successful education-training environment are of great importance in realizing the desired changes in the individual, and it has been thought that the ability to create this environment is directly proportional to the teacher's self-efficacy belief. It has been considered important that the classroom teachers working at elementary school period which is one of the most important steps of primary education, have qualifications as high self-efficacy beliefs, specialists, equipped and able to use various methods-techniques. It has been considered necessary that classroom teachers don't neglect the music education carried out in the elementary school period, carry out the music teaching methods for efficiently music education, use the music teaching techniques, are capable of musical learning-teaching strategies, and have the equipment to use music teaching equipment in line with the requirements of music education during the education process. In this study, it was aimed to present the adaptation and validity-reliability studies of the "Problem Determination Scale for Physical Education and Sports Course" developed by Bozdemir (2012) to the determination the self-efficacy of the classroom teachers towards the music lesson.

Literature Review: When the studies were examined, it was determined that many researches were carried out to determine the self-efficacy of the classroom teacher. In the study of Alter, Hays and O'Hara (2009), they aimed to reveal the elementary teacher's competencies towards creative arts. As a result of this study, they concluded that the creative competencies of teachers have affected the quality of artistic learning and development of elementary school students. In the study conducted by Capaldo, Muscat and Tindall-Ford (2014), it was aimed to determine the musical knowledge competencies of the preservice classroom teachers. As a result of the research, it was determined that preservice classroom teachers should have musical knowledge and experience that they can use in the classroom. In the study conducted by Alemdağ, Öncü and Sakallığlu (2014), they aimed to determine the relationship between the attitudes and self-efficacy perceptions of preservice classroom teachers towards physical education lesson while examining them on some variables. As a result of the research, it was determined that the preservice classroom teachers' attitudes towards physical education lesson and their self-efficacy perceptions of physical education lesson are above the middle level. In the study of Dilmaç and İnanç (2015), they aimed to determine the self-efficacy levels of the classroom teachers regarding the visual arts course. As a result of the research, it was determined that the classroom teachers' selfefficacy towards the visual arts course was at a good level, they generally trusted themselves and they considered themselves sufficient about the visual arts course. In the study conducted by Kara (2017), he aimed to indicate the proficiency levels of elementary teachers regarding the teaching of physical education lesson. As a result of the research, it was determined that teachers found themselves sufficient in the areas of classroom management, lesson planning, lesson preparation, measurement and evaluation. Besides, it was found that teachers found themselves partially sufficient in using materials. The high level of self-efficacy beliefs of music teachers working in elementary school level which is one of the most important steps of primary education, will contribute to the effective and productive education and to educate well-equipped individuals. It has been considered important for the child to benefit from music education that can maximize the interests, needs and capacities of the child in primary school period. Therefore, it has been thought that the elementary teacher's being equipped in the field of music education and their having high self-efficacy level will support and shape the child's musical development process. Based on this, the purpose of the study was determined as presentation the adaptation and validity-reliability studies of the "Problem Determination Scale for Physical Education and Sports Course" developed by Bozdemir (2012) to the determination the self-efficacy of the classroom teachers towards the music lesson.

Method: The "Problem Determination Scale for Physical Education and Sports Class" developed by Bozdemir (2012) was enhanced in order to identify the problems faced by elementary teachers in physical education and sports class applications. The ratio of agreeing to expressions on a 5-point Likert-type scale is determined by marking the numbers ranging from "strongly agree" to "strongly disagree". The scale in question consists of 200 classroom teachers. Scale analyzes started with a form with 28 -item, and the final version of the scale was reached as a result of the analysis. Content validity index was calculated as 0.78 by taking the average of the scale validity rates. As a result of the analysis made for the reliability of the scale, the Cronbach Alpha coefficients for the entire scale and its sub-dimensions were determined, respectively: .753 for

Turkish Studies - Education, 15(4) 
application problems sub-dimension, .761 for physical problems sub-dimension, .594 for minority problems sub-dimension and .559 for formation problems sub-dimension.

In the process of adapting the "Problem Determination Scale for Physical Education and Sports Course" as "Self-Efficacy Scale for Music Education of Class Teachers", the scale has been applied to 252 classroom teachers working in the elementary schools affiliated to the Uşak Provincial Directorate of National Education. Kaiser-Meyer-Olkin sample suitability test for determining whether the data obtained from the application of the scale is suitable for factor analysis and Factor Analysis for determining the factor structure of the scale were performed. Cronbach Alpha coefficient was also calculated to test its validity.

Finding: As a result of the factor analysis, 7 th item and 16th item were removed from the analysis on the grounds that they gathered under 3 dimensions by taking very close values and decreased reliability. Statistical studies on 20 items remaining in the scale have been included in the findings section. The results of Kaiser-Meyer-Olkin test (0.739) and the Barlett test $(000$ (p.001)) that were done in order to determine the suitability of the data obtained from the adaptation of the scale for factor analysis, has indicated the suitability of the data for factor analysis. 5 factors with an eigenvalue of 1 and above were formed as a result of the principal components analysis which was applied to be able to analyze the dataset with factor analysis. In the analysis, the number of important factors was defined as 5 according to the eigenvalue criterion. The variance explained by these 5 factors on the scale is $56.358 \%$. Vatimax vertical rotation was made in order to provide a better interpretation to the factor analysis. Cronbach Alpha internal consistency coefficients of the subdimensions were calculated after the operation performed to test the reliability of the scale, and the overall Cronbach Alpha internal consistency coefficient of the scale was found to be 0.743 .

Conclusion and Suggestions: The factors of the scale were named as the importance of the lesson, professional competence, physical environment, effective music education and the importance of the field teacher. As a result of the analysis, it can be said that the adaptation of "Problem Determination Scale for Physical Education and Sports Course" as "Self-Efficacy Scale of Classroom Teachers towards Music Education" is a valid and reliable measurement tool.

The original form of the scale consists of 22 items and 4 factors. The items in the original form which are "Lesson hour is sufficient for this lesson to be taught" and "The lesson being done at classroom does not make the students happy", have been below the limit. While first item has been thought to be due to the lack of music education of the classroom teachers who constitute the study group, the last item has been thought to be due to the being for original scale towards the physical education lesson.

When the literature has been analyzed, it is seen that there have been studies especially on the preservice classroom teachers' music education self-efficacy. However, it has been seen that the studies are not sufficient, which are to determine the suitability of the music education activities carried out by the classroom teachers in the school environment to the requirements of the music education, classroom teacher's competencies, effective music education practices and the suitability of the physical environment. It has been expected that this scale, which is adapted for the determination of the classroom teacher's music education selfefficacy, will make an important contribution to the field. In addition to this, it has been thought that it will contribute to determine which level classroom teacher's music education self-efficacy is and to make healthier studies for elementary school music education in line with the obtained results by this adapted scale.

Keywords: Music Education, Class Teacher, Self- Efficacy, Scale Adaptation, Reliability and Validity

Öz: Bireyin müzikal alg1-bilgisini, estetik düşüncesini, yaratıcılığını ve yeteneğini, bireysel ve toplumsal ilişkilerini, zihinsel becerilerini geliştirme vb. özel amaçları doğrultusunda gerçekleştirilen müzik eğitiminde sınıf öğretmeninin müzik alan bilgisinin yeterli olması ve eğitim sürecinde bu alan bilgisini kullanabilmesi önemli görülmektedir. Bu nedenle temel eğitimin önemli basamaklarından biri olan ilkokul kademesinde görev yapan sınıf öğretmenlerinin müzik eğitimine yönelik öz- yeterlik inançlarının yüksek olması gerçekleştirilecek olan eğitimin etkili-verimli olmasına ve donanımlı bireylerin yetişmesine katkı sağlayacaktır. Müzik eğitimi etkinlikleri çocukların yalnızca akademik başarılarına değil aynı zamanda kimlik gelişimlerine, arkadaşlık ilişkilerinin ve sosyal iletişimlerinin gelişimlerine de katkı sağlamaktadır. Bu nedenle ilkokul döneminde çocuğun ilgi, ihtiyaç ve kapasitesini mümkün olan en üst düzeye çıkarabilecek müzik eğitiminden yararlanması önemli görülmekte; sınıf öğretmeninin müzik eğitimi alanında donanımlı olması ve öz-yeterlik düzeyinin 
yüksek olmasının çocuğun müziksel gelişim sürecini destekleyip şekillendireceği düşünülmektedir. Bu düşünce ile bu araştırmada Bozdemir (2012) tarafindan geliştirilen "Beden Eğitimi ve Spor Dersine Yönelik Problem Belirleme Ölçeği”nin sınıf öğretmenlerinin müzik dersine yönelik öz-yeterliklerini belirlemeye yönelik uyarlama ve geçerlik-güvenirlik çalışmalarının sunulması amaçlanmıştır. Araştırma Uşak İl Milli Eğitim Müdürlüğünün 5445474 sayı ve 14 Mart 2019 tarihli izni ile Uşak İl Milli Eğitim Müdürlüğüne bağlı ilkokullarda görev yapan 252 sınıf öğretmeniyle yürütülmüştür. 5'li likert tipindeki ölçeğin geçerlik ve güvenirlik çalışmaları sonucunda ölçeğin müzik dersine yönelik öz-yeterlik ölçeğine uyarlanmış şeklinin 5 faktöre dağılan 20 maddeden oluştuğu saptanmıştır. Ölçeğin uygulanmasından elde edilen verilerin faktör analizi için uygun olup olmadığının belirlenmesinde Kaiser-Meyer-Olkin (KMO) örneklem uygunluğu testi ve ölçeğin faktör yapısını belirlemek üzere faktör analizi yapılmış geçerliğini test etmek üzere Cronbach Alfa kat sayısı belirlenmiştir ve 0.743 olarak hesaplanmıştır. Veri kümesini faktör analiziyle analiz edebilecek duruma getirmek için uygulanan temel bileşenler analiz sonucunda öz değeri 1 ve üzerinde olan 5 faktör oluşmuştur. Elde edilen sonuçlara göre, sınıf öğretmenlerinin müzik eğitimine yönelik öz-yeterliklerini ölçmek için uyarlanan ölçeğin uygun bir ölçme aracı olduğu söylenebilir.

Anahtar Kelimeler: Müzik Eğitimi, Sınıf Öğretmeni, Öz-Yeterlik, Ölçek Uyarlama, Güvenirlik ve Geçerlik

\section{Giriş}

Bireyin toplum yaşamında yerini almas için gerekli bilgi, beceri ve anlayışı elde etmesinde; kişiliğinin gelişmesinde önemli katkıları olan eğitim süreci ailede başlamakta, kurumsal olarak ise okul öncesi dönemde başlayıp zorunlu eğitim döneminde de devam etmektedir. Bu kapsamda bireyde istenilen değişimlerin gerçekleşmesinde öğretmenin donanımı ve etkili-başarılı bir eğitim-öğretim ortamı oluşturabilmesi büyük önem taşımakta; bu ortamın oluşturabilmesinin öğretmenin öz-yeterlik inancı ile doğru orantılı olduğu düşünülmektedir. Öğretmenin öz-yeterlik inanc1 eğitim ortamında öğrencinin öğrenmesini etkileyecek girdileri sağlayabilme yeteneğine olan inancı olarak tanımlanabilir (Kalaycı \& Bayrak, 2016).

Öz-yeterlik inancının yüksek olması öğretmenin öğrencileriyle sağlıklı iletişim kurabilmesine, eğitim süreci içerisinde farklı öğretim yöntemleri kullanarak daha etkili bir öğrenme ortamı sunmasına, mesleğini en iyi şekilde ortaya koymasına, etkili bir öğrenme-öğretme süreci içerisinde uygun yöntem ve teknikleri seçmesine ve başarılı bir öğretim sürecini yürütmesine katk1 sağlayacaktır (Koç, Akran \& Bakır, 2019; Saracaloğlu, Aldan Karademir, Dinçer \& Dedebali 2017; Yaşar Ekici, 2017). Bu inancın zayıf olması ise öğretmenin kendisinden şüphe duymasına, öğretim sürecindeki zorluklarla mücadele etme konusunda zayıf olmasına, sıklıkla stres ve endişe durumunu yaşamasına neden olabilmektedir (Kıvanç, 2020).

$\mathrm{Bu}$ kapsamda temel eğitimin önemli basamaklarından biri olan ilkokul döneminde görev yapan sınıf öğretmenlerinin öz-yeterlik inancı yüksek, alanında uzman, donanımlı, çeşitli yöntem ve teknikleri kullanabilecek niteliğe sahip olmaları önemli görülmektedir. Çünkü sınıf öğretmenliği alanı birçok disiplini bünyesinde barındırmakta, sınıf öğretmeni bu alanların öğretimini yapmakta ve öğrencilerinin çok yönlü gelişimlerine katkıda bulunmaktadır (Çaycı, 2011; Güven \& Gökdağ Baltaoğlu, 2017). Bu nedenle sınıf öğretmenlerinin pek çok yönden yeterlik kazanması alan ve öğretmenlik meslek bilgilerinin tam ve doğru olması büyük önem taşımaktadır (Çayc1, 2011).

İlkokul döneminde Türkçe, matematik, fen bilimleri, sosyal bilgiler, hayat bilgisi, beden eğitimi, görsel sanatlar, trafik ve müzik gibi farklı birçok dersin eğitimi sınıf öğretmeninin sorumluluğunda gerçekleşmektedir. Bu süreçte öğrencide istenilen yönde davranış değişikliğinin meydana gelmesi hedeflenmekte; sadece öğrencinin akademik yöndeki gelişimi değil aynı zamanda psikomotor, duygusal ve sosyal gelişimi de bu süreç içerisinde desteklenmektedir. Bu kapsamda bilişsel, devinişsel ve duyuşsal alandaki gelişimlerini destekleyici nitelikte olduğu düşünülen müzik eğitiminin öğrencinin gelecekte müziğe karşı geliştireceği ilgi, tutum ve davranışları etkileyeceği (Gülle, Uzun \& Akay, 2018); müzikal beğeni düzeyinin ve estetik algısının da oluşumuna katkı 
sağlayacağ düşünülmektedir. Bu nedenle ilkokul dönemindeki müzik eğitiminin etkili ve verimli bir süreç içerisinde gerçekleştirilmesi önemli görülmektedir.

Bu düşünce ile ilkokul döneminde gerçekleştirilen müzik eğitiminin ihmal edilmemesi, müzik dersini yapan sınıf öğretmenlerinin etkili müzik öğretiminin gerçekleştirilmesine yönelik olarak müzik öğretim yöntemleri, müzik öğretim teknikleri, müzikal öğrenme-öğretme stratejileri açısından yeterli olmaları; müzik öğretim araç-gereçlerini eğitim süreci içerisinde müzik eğitiminin gerekleri doğrultusunda kullanabilecek donanıma sahip olmaları gerekli görülmektedir (Uçan, Yıldız \& Bayraktar, 1999).

Yapılan çalışmalar incelendiğinde sınıf öğretmeninin öz-yeterliğinin tespitine ilişkin pek çok araştırmanın yapıldığı belirlenmiştir.

Alter, Hays ve O'Hara (2009) yapmış oldukları çalışmada sınıf öğretmeninin yaratıcı sanatlara yönelik yeterliklerini ortaya koymayı amaçlamış; araştırmanın sonucunda öğretmenlerin yaratıcılık yeterliklerinin ilköğretim öğrencilerinin sanatsal öğrenme ve gelişim kalitesini etkilediği sonucuna ulaşılmıştır.

Capaldo, Muscat ve Tindall-Ford (2014) tarafından yapılan çalışmada sınıf öğretmeni adaylarının müzik bilgisi yeterliklerinin belirlenmesi amaçlanmış; araştırmanın sonucunda öğretmen adaylarının sınıf ortamında kullanabilecekleri müzikal bilgi ve deneyimlere sahip olmalarının gerekli olduğu tespit edilmiştir.

Alemdağ, Öncü ve Sakallığlu (2014) yapmış oldukları çalışmalarında sınıf öğretmeni adaylarının beden eğitimi dersine yönelik tutum ve öz-yeterlik algılarını bazı değişkenlere göre inceleyip aralarındaki ilişkiyi belirlemeyi amaçlamışlardır. Araştırmanın sonucunda sınıf öğretmeni adaylarının beden eğitimi dersine yönelik tutumlarının ve beden eğitimi dersi öz-yeterlik algılarının orta seviyenin üzerinde olduğu belirlenmiştir.

Dilmaç ve İnanç (2015) yapmış oldukları çalışmada sınıf öğretmenlerinin görsel sanatlar dersine ilişkin öz-yeterlik düzeylerini tespit etmeyi amaçlamış; araştırmanın sonucunda sınıf öğretmenlerinin görsel sanatlar dersine yönelik öz-yeterliklerinin iyi düzeyde olduğu, genel olarak kendilerine güvendikleri ve görsel sanatlar dersi konusunda kendilerini yeterli gördükleri belirlenmiştir.

Kara (2017) yapmış olduğu çalışmada sınıf öğretmenlerinin beden eğitimi dersi öğretimine ilişkin yeterlik düzeylerinin belirlenmesini amaçlamış; araştırmanın sonucunda öğretmenlerin kendilerini sınıf yönetimi, dersi planlama ve ders hazırlığı uygulama, ölçme ve değerlendirme alanlarında yeterli buldukları belirlenmiştir. Öğretmenlerin materyal kullanımında ise kendilerini kısmen yeterli buldukları tespit edilmiştir.

Bireyin müzikal algı-bilgisini, estetik düşüncesini, yaratıcılığını ve yeteneğini, bireysel ve toplumsal ilişkilerini, zihinsel becerilerini geliştirme vb. özel amaçları (Milli Eğitim Bakanlığı [MEB], 2018) doğrultusunda gerçekleştirilen müzik eğitiminde sınıf öğretmeninin müzik alan bilgisinin yeterli olması ve eğitim sürecinde bu alan bilgisini kullanabilmesi önemli görülmektedir. Bu nedenle temel eğitimin önemli basamaklarından biri olan ilkokul kademesinde görev yapan sınıf öğretmenlerinin müzik eğitimine yönelik öz-yeterlik inançlarının yüksek olması gerçekleştirilecek olan eğitimin etkili-verimli olmasına ve donanımlı bireylerin yetişmesine katkı sağlayacaktır.

Müzik eğitimi etkinlikleri çocukların yalnızca akademik başarılarına değil aynı zamanda kimlik gelişimlerine, arkadaşlık ilişkilerinin ve sosyal iletişimlerinin gelişimlerine de katk1 sağlamaktadır (Aksu, 2007; akt: Haskan Avc1, 2015; Karaca, Sarı \& A ğca, 2017). Bu nedenle ilkokul döneminde çocuğun ilgi, ihtiyaç ve kapasitesini mümkün olan en üst düzeye çıkarabilecek müzik eğitiminden yararlanması önemli görülmekte; sınıf öğretmeninin müzik eğitimi alanında donanımlı olması ve öz-yeterlik düzeyinin yüksek olmasının çocuğun müziksel gelişim sürecini destekleyip 
şekillendireceği düşünülmektedir. Buradan yola çıkarak bu araştırmanın problem cümlesi; Bozdemir (2012) tarafindan geliştirilen "Beden Eğitimi ve Spor Dersine Yönelik Problem Belirleme Ölçeği”" sınıf öğretmenlerinin müzik dersine yönelik öz-yeterliklerini belirlemek için nasıl uyarlanabilir? biçiminde oluşturulmuş̧ur.

Çocuğun sosyal, psikolojik vb. gelişimsel özelliklerine önemli katkıları olduğu düşünülen ilkokul dönemi müzik eğitimini gerçekleştiren sınıf öğretmenlerinin müzik eğitimi alan yeterliklerinin ne düzeyde olduğunun tespit edilmesi gerekli görülmektedir. Bu çalışma söz konusu alan yeterliklerinin ne düzeyde olduğunun tespitine yönelik bir ölçeğin geliştilmesi, bu tespitlere yönelik iyileştirmelerin yapılabilmesi ve buna yönelik yeni ararştırmalara yol gösterecek olması açısından önemli görülmektedir.

$\mathrm{Bu}$ amaçla bu çalışmada sınıf öğretmenlerinin müzik dersine yönelik öz-yeterliklerinin ne düzeyde olduğunun tespitine yönelik olarak Bozdemir (2012) tarafından geliştirilen "Beden Eğitimi ve Spor Dersine Yönelik Problem Belirleme Ölçeği” nin uyarlanması amaçlanmıştır. Araştırmanın amacına bağlı olarak aşağıdaki sorulara cevap aranmıştır:

1. Ölçeğin KMO ve Barlett Test sonuçları nelerdir?

2. Ölçeğin toplam varyans dağıllımlarına ilişkin sonuçlar nelerdir?

3. K-MPKE’nin faktör yapısına ilişkin sonuçlar nelerdir?

4. Sınıf öğretmelerinin müzik eğitimi uygulamalarında karşılaştıkları problemlere yönelik ölçekle ilgili faktörlere göre Cronbach's Alpha (iç tutarlık) katsayılarına ilişkin sonuçlar nelerdir?

\section{Yöntem}

\section{Araştırmanın Modeli}

Bu çalışmada tarama modeli kullanılmıştır. Bu tür araştırmalarda büyük bir topluluğun bir konuya ilişkin inanç, tutum, kaygı vb. görüşleri belirlenmektedir (akt: Katrancı \& Şengül, 2020).

Çalışma Grubu: Araştırma verileri Uşak İl Milli Eğitim Müdürlüğünün 5445474 sayı ve 14 Mart 2019 tarihli izni ile 2019-2020 eğitim öğretim yılında Uşak İl Milli Eğitim Müdürlüğüne bağl1 ilkokullarda görev yapan 252 öğretmene ulaşılarak toplanmıştır. Katılımcılar anketi gönüllülük esasına dayalı olarak doldurmuşlardır. Ölçeği cevaplayan 252 öğretmenin demografik özelliklerini içeren bilgilere Tablo 1' de yer verilmiştir.

Tablo 1: Sınıf Öğretmenlerinin Demografik Bilgileri

\begin{tabular}{lcc}
\hline Cinsiyet & $\mathbf{N}$ & $\mathbf{\%}$ \\
\hline Erkek & 112 & 44,4 \\
Kadın & 140 & 55,6 \\
Toplam & $\mathbf{2 5 2}$ & $\mathbf{1 0 0}$ \\
\hline Yaş & $\mathbf{N}$ & $\mathbf{\%}$ \\
\hline $24-30$ & 18 & 7,1 \\
$31-37$ & 44 & 17,5 \\
$38-44$ & 74 & 29,4 \\
$45-51$ & 97 & 38,5 \\
52 ve üzeri & 19 & 7,5 \\
Toplam & $\mathbf{2 5 2}$ & $\mathbf{1 0 0}$ \\
\hline Hizmet Yll Süreleri & $\mathbf{N}$ & $\mathbf{\%}$ \\
\hline 10 yıl ve altı & 23 & 9,1 \\
11-20 y1lı aras1 & 72 & 28,6 \\
21 y1l ve üstü & 157 & 62,3 \\
Toplam & $\mathbf{2 5 2}$ & $\mathbf{1 0 0}$ \\
\hline
\end{tabular}

Turkish Studies - Education, 15(4) 


\begin{tabular}{lcc}
\hline Mezuniyet Alanı & N & \% \\
\hline Sınıf Öğretmenliği & 214 & 84,9 \\
Diğer Alanlar & 38 & 15,1 \\
Toplam & $\mathbf{2 5 2}$ & $\mathbf{1 0 0}$ \\
\hline Formasyon Alma Durumu & $\mathbf{N}$ & $\mathbf{\%}$ \\
\hline Evet & 47 & 18,7 \\
Hayır & 205 & 81,3 \\
Toplam & $\mathbf{2 5 2}$ & $\mathbf{1 0 0 , 0}$ \\
\hline
\end{tabular}

Tablo 1'de de görüldüğü gibi araştırmaya katılan sınıf öğretmenlerinin \%55,6'sını kadınlar, $\% 44,4$ 'nü ise erkekler oluşturmaktadır. Öğretmenlerin \%7,1'inin 24-30, \%17,5'inin 31-37, $\% 29,4$ 'ünün $38-44, \% 38,5$ 'inin $45-51$ yaş grubunda, $\% 7,5$ 'inin ise 52 yaş ve üstü grupta olduğu; $\% 9,1$ 'inin 10 yıl ve altı, \%28,6'sının 11-20, \%62,3'ünün ise 21 yıl ve üzeri hizmet yılına sahip olduğu görülmektedir. Bununla birlikte öğretmenlerin \% 15 'inin alan dışından mezun olup formasyon aldığı, \%81,3’ünün ise sınıf öğretmenliği bölümlerinden mezun olduğu görülmektedir.

Ölçme Aracı: Bozdemir (2012) tarafından geliştirilen "Beden Eğitimi ve Spor Dersine Yönelik Problem Belirleme Ölçeği" sınıf öğretmenlerinin beden eğitimi ve spor dersi uygulamalarında karşılaștıkları problemleri tespit etmek amacıyla geliștirilmiștir. 5'li likert tipindeki ölçekte ifadelere katılma oranı "tamamen katılıyorum" ile "hiç katılmıyorum" arasında değişmektedir. Ölçek 200 sınıf öğretmenine uygulanmıştır.

Ölçek analizlerine 28 maddelik form ile başlamış, analizler sonucunda ölçeğin son haline ulaşılmıştır. Ölçek geçerlik oranlarının ortalaması alınarak kapsam geçerlik indeksi 0.78 açıklamıştır. Ölçeğin güvenirliği için yapılan analizler sonucunda ölçeğin tamamı ve alt boyutlarına ilişkin Cronbach Alfa katsayıları sırasıyla; uygulama problemleri alt boyutu için .753, fiziksel problemler alt boyutu için .761, önemseme problemleri alt boyutu için .594 ve formasyon problemleri alt boyutu için .559 olarak belirlenmiştir.

İşlem: "Beden Eğitimi ve Spor Dersine Yönelik Problem Belirleme Ölçeği” nin "Sınıf Öğretmenlerinin Müzik Eğitimine Yönelik Öz-Yeterlikleri” ni tespit etme amacına yönelik olarak kullanılmak üzere uyarlanması sürecinde ölçek Uşak İl Milli Eğitim Müdürlüğüne bağglı ilkokullarda görev yapan 252 sınıf öğretmenine uygulanmıştır. Ölçeğin uygulanmasından elde edilen verilerin faktör analizi için uygun olup olmadığının belirlenmesinde Kaiser-Meyer-Olkin örneklem uygunluğu testi ve ölçeğin faktör yapısını belirlemek üzere faktör analizi yapılmış; geçerliğini test etmek üzere Cronbach Alfa kat sayısı hesaplanmıştır.

\section{Bulgular}

\section{KMO ve Barlett Testleri Sonuçlarına İlişkin Bulgular}

Yapılan faktör analizi sonucunda 7. ve 16. maddeler birbirine çok yakın düzeyde değer alarak 3 boyutun altında toplandığı ve güvenirliği düşürmesi gerekçeleri ile analizden çıkarılmıştır. Bulgular bölümünde ölçekte kalan 20 madde üzerinden yapılan istatistiksel çalışmalara yer verilmiştir. Tablo 2'de ölçeğin uyarlamasından elde edilen verilerin faktör analizi için uygunluğunun belirlenebilmesi için yapılan Kaiser-Meyer-Olkin (KMO) örneklem uygunluğu testi ve Barlett Küresellik testinin sonuçları gösterilmiştir.

Tablo 2: KMO ve Barlett Testleri Sonuçları

\begin{tabular}{lll}
\hline Kaiser-Meyer-Olkin(KMO) & Örneklem uygunluk değeri & 0,739 \\
\hline \multirow{3}{*}{ Bartlett Küresellik Testi } & Yaklaşık Ki-Kare Değeri & 1457,746 \\
& Serbestlik Derecesi (df) & 190 \\
& Anlamlılık Seviyesi Sig. &, 000 \\
\hline
\end{tabular}


Kaiser-Meyer-Olkin (KMO)'nin 0,60'dan yüksek, Barlett testinin de anlamlı çıkması verilerin faktör analizi için uygun olduğunu göstermektedir (Alpar, 2013). Tablo 2 incelendiğinde ölçeğe ait KMO değerinin 0.739 ve Barlett Küresellik Testi değerinin de .000 (p.001) olduğu görülmektedir.

\section{Toplam Varyans Dağılımlarına İlişkin Bulgular}

Veri kümesini faktör analiziyle analiz edebilecek duruma getirmek için uygulanan temel bileşenler analizi sonucunda öz değeri 1 ve üzerinde olan 5 faktör oluşmuştur. Elde edilen sonuçlara Tablo 3'te yer verilmiştir.

Tablo 3: Açıklanan Toplam Varyans Dağılımları

\begin{tabular}{|c|c|c|c|c|c|c|}
\hline \multirow[t]{2}{*}{ Bileşen } & \multicolumn{3}{|c|}{ Başlangıç Özdeğeri } & \multicolumn{3}{|c|}{ Kareli Yük Toplamlarının İlk Hali } \\
\hline & Toplam & Varyans $(\%)$ & Kümülatif (\%) & Toplam & Varyans $(\%)$ & Kümülatif (\%) \\
\hline 1 & 3,898 & 19,490 & 19,490 & 3,898 & 19,490 & 19,490 \\
\hline 2 & 2,910 & 14,550 & 34,040 & 2,910 & 14,550 & 34,040 \\
\hline 3 & 1,999 & 9,996 & 44,036 & 1,999 & 9,996 & 44,036 \\
\hline 4 & 1,355 & 6,775 & 50,811 & 1,355 & 6,775 & 50,811 \\
\hline 5 & 1,109 & 5,547 & 56,358 & 1,109 & 5,547 & 56,358 \\
\hline . & $\cdot$ & $\cdot$ & $\cdot$ & & & \\
\hline . & . & . & . & & & \\
\hline$\cdot$ & $\cdot$ & . & . & & & \\
\hline 20 & ,232 & 1,161 & 100,000 & & & \\
\hline
\end{tabular}

\section{K-MPKE'nin Faktör Yapısına İlişskin Bulgular}

Analizde önemli faktör sayısı özdeğer ölçütüne göre 5 olarak tanımlanmıștır. Bu 5 faktörün ölçeğe ilişkin açıkladıkları varyans \%56.358'dir. Faktör analizine daha iyi yorum getirebilmek için Vatimax dik döndürme yapılmış, elde edilen faktörler ve faktörlerin içerdikleri maddeler Tablo 4'te verilmiştir.

Tablo 4: K-MPKE’nin Faktör Yapısı

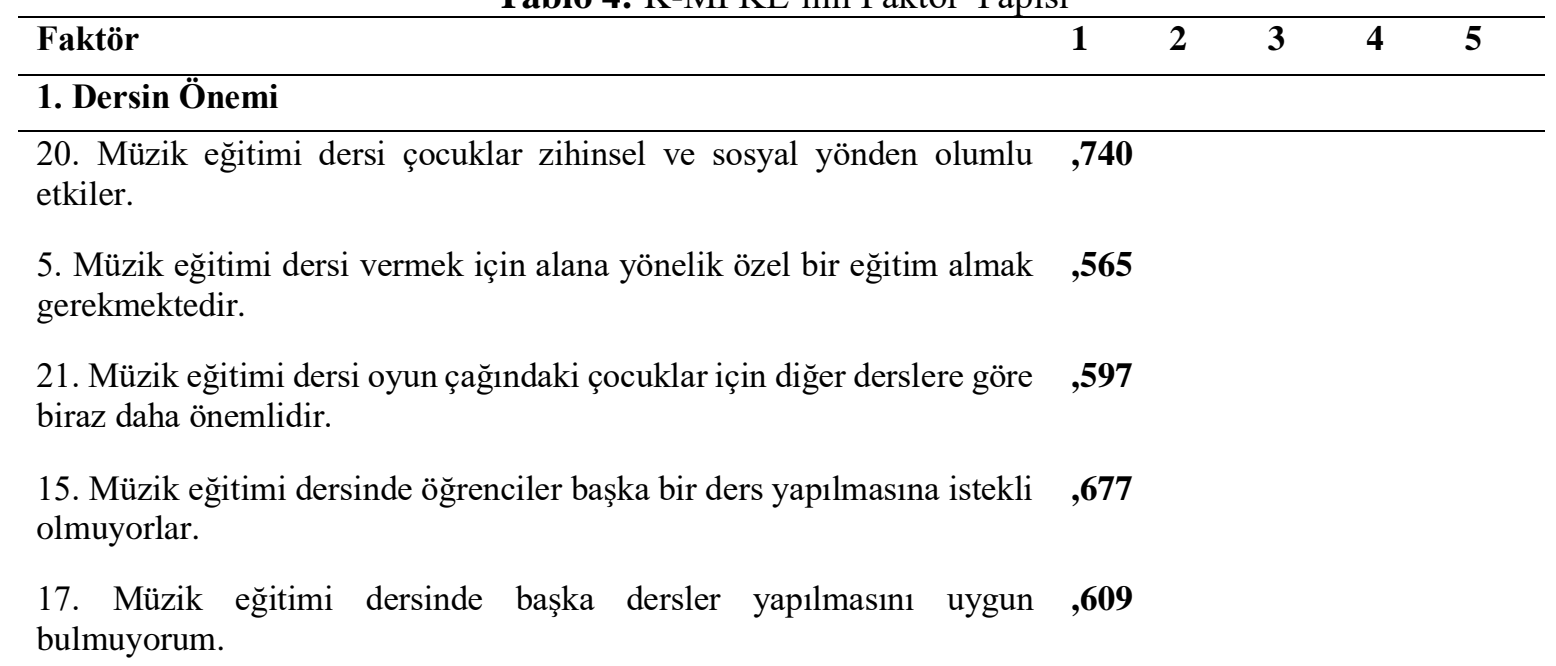


22. Müzik eğitimi dersinde kalıcı davranış biçimlerinin kazanıldığını ,508 , 316 gözlemliyorum.

\section{Mesleki Yeterlik}

1.Müzik eğitimi dersi vermek için yüksek öğretimde aldığım dersler yeterlidir.

2. Müzik eğitimi dersinin amaç ve ilişkilerini yeterince biliyorum.

13. Müzik eğitimi dersinde çocuklara müziği sevdirdiğime ve müzik

\begin{tabular}{|c|c|}
\hline 3. Fiziki Ortam & \\
\hline $\begin{array}{l}\text { 6. Müzik eğitimi dersinin işlenebilmesi için okul yönetimi yeterince } \\
\text { katkıda bulunmaktadır. }\end{array}$ & ,681 \\
\hline 8. Müzik eğitimi dersi için okulun fiziki koşulları yeterlidir. & ,819 \\
\hline 9. Müzik eğitimi dersi için okul araç ve gereçleri yeterlidir. & ,771 \\
\hline
\end{tabular}

\begin{tabular}{|c|c|c|c|}
\hline 4.Etkili Müzik Eğitimi & & & \\
\hline $\begin{array}{l}\text { 4. Müzik eğitimi konusunda formasyon almak bu dersin etkililiğini } \\
\text { arttırır. }\end{array}$ & & ,614 & \\
\hline $\begin{array}{l}\text { 10. Müzik eğitimi dersi için yeterli alan ve malzemenin olması dersin } \\
\text { etkililiğini arttırır. }\end{array}$ & ,365 &, 501 & \\
\hline 11. Müzik dersine müzik eğitimine yönelik araç-gereçle katılıyorum. &, 312 & ,672 & \\
\hline $\begin{array}{l}\text { 12. Müzik dersine çocukların müzik dersi malzemeleriyle katılmalarına } \\
\text { dikkat ediyorum. }\end{array}$ & & ,770 & \\
\hline \multicolumn{4}{|l|}{ 6. Alan Öğretmeninin Önemi } \\
\hline $\begin{array}{l}\text { 18. Müzik dersi sınıf öğretmenlerinin ders yoğunluğunun fazla } \\
\text { olmasından dolayı pek yapılmıyor. }\end{array}$ & & & ,829 \\
\hline $\begin{array}{l}\text { 19. Müzik dersine müzik eğitimi öğretmenlerinin girmesi daha yararlı } \\
\text { olacaktır. }\end{array}$ &, 595 & & ,539 \\
\hline
\end{tabular}

Sınıf Öğretmelerinin Müzik Eğitimi Uygulamalarında Karşılaştıkları Problemlere Yönelik Ölçekle İlgili Faktörlere Göre Cronbach's Alpha (İç Tutarlık) Katsayılarına İlişkin Bulgular

Ölçeğin güvenirliğini test etmek üzere yapılan işlem sonrasında alt boyutların Cronbach Alfa iç tutarlık katsayıları hesaplanmış faktörlere ilişkin bu katsayılar Tablo 5 'te verilmiştir. 
Tablo 5: Sınıf Öğretmelerinin Müzik Eğitimi Uygulamalarında Karşılaştıkları Problemlere Yönelik Ölçekle İlgili Faktörlere Göre Cronbach's Alpha (İç Tutarlık) Katsayıları

\begin{tabular}{cc}
\hline Boyutlar & Cronbach Alpha Katsayları \\
\hline 1.Boyut & 0,711 \\
2.Boyut & 0,742 \\
3.Boyut & 0,706 \\
4.Boyut & 0,614 \\
5.Boyut & 0,408 \\
\hline
\end{tabular}

Ölçeğin genel Cronbach Alfa iç tutarlık katsayısı ise 0.743 olarak bulunmuştur.

\section{Tartışma ve Sonuç}

$\mathrm{Bu}$ araştırmanın amacı "Beden Eğitimi ve Spor Dersine Yönelik Problem Belirleme Ölçeği”"ni sınıf öğretmenlerinin müzik eğitimine yönelik problemlerinin tespitine yönelik olarak uyarlamak ve ölçeğin geçerlik-güvenirlik çalışmasını sunmaktır. 252 öğretmenden elde edilen verilerin analizi sonucunda 20 maddelik ölçeğin 5 alt boyutu olduğu ve Cronbach Alfa güvenirlik kat sayısının 0.743 olduğu belirlenmiştir. Ölçeğin faktörleri dersin önemi, mesleki yeterlik, fiziki ortam, etkili müzik eğitimi, alan öğretmeninin önemi olarak adlandırılmıştır. Yapılan analizler sonucunda "Beden Eğitimi ve Spor Dersine Yönelik Problem Belirleme Ölçeği”"nin "Sınıf Öğretmenlerinin Müzik Eğitimine Yönelik Öz-Yeterliklerinin" tespitine yönelik ölçek olarak uyarlamasının geçerli ve güvenilir bir ölçme aracı olduğu söylenebilir.

Ölçeğin orijinal formu 22 madde 4 faktörden oluşmaktadır. Orijinal formunda yer alan "Ders saati bu dersin işlenmesi için yeterlidir" ve "Dersin sınıfta yapılması öğrencileri mutlu etmiyor" maddeleri sınırın altında kalan maddelerdir. $\mathrm{Bu}$ durumun çalışma grubunu oluşturan sınıf öğretmenlerinin müzik eğitimi yetersizliklerinden, diğer maddenin ise orijinal ölçeğin beden eğitimi dersine yönelik olmasından kaynaklandığg düşünülmektedir.

Sınıf öğretmeninin müzik eğitimi alan yeterliklerinin iyi düzeyde olması öğrencinin tüm gelişimsel alanlarını etkileyen ve şekillendiren bir durumdur. Köksoy Mentiş (2017)'in yaptığı araştırmada sınıf öğretmenlerinin enstrüman çalma durumlarının müzikte uygulama becerileri açısından enstrüman çalamayan sınıf öğretmenlerine göre anlamlı bir fark olduğu sonucuna ulaşmıştır. $\mathrm{Bu}$ durum sınıf öğretmenlerinin çalgı çalma becerilerinin yüksek olmasının sınıfta gerçekleştirecekleri müzik etkinliklerinin yetkinliğini ve sınıf öğretmeni müzik eğitimi öz-yeterlik düzeyini olumlu yönde etkileyeceğini düşündürmektedir.

Gülle ve Akay (2019) yapmış oldukları çalışmada sınıf öğretmeni adaylarının müzik eğitimi öz-yeterlik inançlarının, müzik kavramına yönelik yazılı ve görsel metaforlarının incelenmesini amaçlamışlardır. Çalışmanın sonucunda sınıf öğretmeni adaylarının müzik eğitimi öz-yeterlik algilarının orta düzeyde olduğu sonucuna ulaşılmıştır. Köksoy Mentiş (2017) ve Gülle ve Akay (2019)'ın yapmış olduğu çalışmalardan elde edilen bu bulgu sınıf öğretmeni adaylarının müzik eğitimi öz-yeterliklerinin orta seviyede olduğu ve bu durumun sınıf öğretmeninin gerçekleştireceği müzik eğitimin etkili ve verimli olmasını etkileyeceği düşünülmektedir.

Çelik (2018) yapmış olduğu çalışmada sınıf öğretmeni adaylarının müzik öğretimine yönelik tutumları ve öz-yeterlik inançları arasındaki ilişkiyi incelemiş ve araştırmanın sonucunda müzik öğretimine ilişkin tutum ile öz-yeterlik algısı arasında pozitif yönde bir ilişkinin olduğunu belirlemiştir. Çelik'in yapmış olduğu çalışma da yukarıdaki çalışmalarla benzerlik göstermektedir.

Literatür incelendiğinde özellikle sınıf öğretmeni adaylarının müzik eğitimi öz-yeterliklerine ilişkin çalışmalar yapıldığ 1 görülmektedir. Ancak özellikle sınıf öğretmenlerinin okul ortamında gerçekleştirdikleri müzik eğitimi etkinliklerinin müzik eğitimi gereklerine uygunluğu, sınıf öğretmeni yeterlikleri, etkin müzik eğitimi uygulamaları ve fiziksel ortamın uygunluğunun tespitine yönelik çalışmaların yeterli olmadığı görülmektedir. Sınıf öğretmeninin müzik eğitimi öz 
yeterliğinin tespitine yönelik olarak uyarlanan bu ölçeğin alana önemli bir katk1 sağlayacağ1 beklenmektedir. Bununla birlikte uyarlanan bu ölçekle sınıf öğretmenlerinin müzik eğitimi özyeterliklerinin ne düzeyde olduğunun tespit edilmesi ve elde edilen sonuçlar doğrultusunda ilkokul müzik eğitimine yönelik daha sağlıklı çalışmaların yapılmasına katkı sağlanacağı düşünülmektedir.

\section{Kaynakça}

Alemdağ, S., Öncü, E., \& Sakallığlu, F. (2014). Sınıf öğretmeni adaylarının beden eğitimi dersine yönelik tutum ve öz-yeterlikleri. Abant İzzet Baysal Üniversitesi Eğitim Fakültesi Dergisi, 14(2), 45-60. https://doi.org/10.17240/aibuefd.2014.14.2-5000091527

Alpar, R. (2013). Uygulamalı çok değişkenli istatistik yöntemler (4. basım). Detay Yayıncılık.

Alter, F., Hays, T., \& O'Hara, R. (2009). Creative arts teaching and practice: Critical reflections of primary school teachers in Australia. International Journal of Education \& The Arts, 10(9), $1-22$.

Bozdemir, R. (2012). Sınıf öğretmenlerinin beden eğitimi ve spor dersinde karşılaştıkları problemlere yönelik ölçek geliştirme çalışması [Yayımlanmamış yüksek lisans tezi]. Gazi Üniversitesi Eğitim Bilimleri Enstitüsü. https://doi.org/10.1501/sporm_0000000254

Capaldo, J., Muscat, B., \& Tindall Ford, S. (2014). Examining pre-service generalist primary teachers' pedagogical content knowledge for teaching music in the K-6 classroom. International Journal of Early Childhood Learning, 20(1), 19-32. https://doi.org/10.18848/2327-7939/cgp/v21i01/48430

Çaycı, B. (2011). Sınıf öğretmenliği lisans programındaki alan eğitimi derslerinin öğretmen yeterliği üzerindeki etkisinin incelenmesi. Mersin Üniversitesi Eğitim Fakültesi Dergisi, 7(2), 1-12. https://doi.org/10.17860/mersinefd.282384

Çelik, Y. (2018). Sınıf öğretmeni adaylarının müzik öğretimine ilişkin tutumları, öz yeterlilik inançları ve müzik yeteneklerine ilişkin öz yeterlilikleri arasındaki ilişkinin incelenmesi [Yayımlanmamış yüksek lisans tezi]. Amasya Üniversitesi Sosyal Bilimler Enstitüsü. https://doi.org/10.9775/kausbed.2017.011

Dilmaç, O., \& İnanç, C. (2015). Sınıf öğretmenlerinin görsel sanatlar dersine yönelik öz yeterlik düzeyleri. Bartın Üniversitesi Eğitim Fakültesi Dergisi, 4(2), 382-400. https://doi.org/10.14686/buefad.v4i2.1082000254

Gülle, A., \& Akay, C. (2019). Sınıf öğretmeni adaylarının müzik öğretimi öz yeterlik inançlarının, müzik kavramına yönelik yazılı ve görsel metaforlarının incelenmesi. Uluslararası Sosyal Araştırmalar Dergisi, 12(62), 1043-1057. https://doi.org/10.17051/ilkonline.2018.466366

Gülle, A., Uzun, N., \& Akay, C. (2018). Ortaokul öğrencilerine yönelik blok flüt icra performans1 dereceli puanlama anahtarının güvenirliğinin genellenebilirlik kuramı ile incelenmesi. İlköğretim Online, 17(3), 1463-1475. https://doi.org/10.17051/ilkonline.2018.466366

Güven, M., \& Gökdağ Baltaoğlu, M. (2017). Öğretmen adaylarının özyeterlik algıları, öğrenme stilleri ve ögrrenme stratejilerinin incelenmesi: Anadolu Üniversitesi örneği. Anadolu Üniversitesi Eğitim Bilimleri Enstitüsü Dergisi, 7(2), 288-337. https://doi.org/10.17240/aibuefd.2017.17.30227-326612

Haskan Avcı, Ö. (2016). Müzik ve kimlik kazanımı bağlamında iki çocuk romanının karşılaştırılması: "Hayta" ve "Yol Arkadaşım Banço". Uluslararası Hakemli İletişim ve Edebiyat Araştırmaları Dergisi, 11, 442-457. https://doi.org/10.37999/udekad.651133 
Karaca, M., Sarı, H., \& Ağca, İ. (2017). Zihinsel engelli bireylerin arkadaş ilişkileri geliştirmede grupla müzik etkinliklerinin öneminin değerlendirilmesi. Gaziantep University Journal of Educational Sciences, 1(1), 1-24.

Kara, İ. (2007). İlköğretimde sınıf öğretmenlerinin beden eğitimi dersi öğretimine ilişkin yeterlik düzeylerinin incelenmesi [Yayımlanmamıș yüksek lisans tezi]. Marmara Üniversitesi Eğitim Bilimleri Enstitüsü. https://doi.org/10.31680/gaunjss.623361

Katranc1, Y., \& Şengül, S. (2020). Matematik ve fen öğretiminde güven, bağlılık, işbirliği ve öğrenci düşüncesi inançları ölçeğinin uyarlama çalışması. Yükseköğretim ve Bilim Dergisi/Journal of Higher Education and Science, 10(1), 114-125.

https://doi.org/10.17679/inuefd.577237

Kavrayıcı, C. \& Bayrak, C. (2016). Öğretmen adaylarının öz-yeterlik algıları. Adıyaman Üniversitesi Sosyal Bilimler Enstitüsü Dergisi, 8 (23), 623-658. https://doi.org/10.14520/adyusbd.70805

Kıvanç, R. (2020). 24-36 aylık çocuğu olan annelerin özyeterlik algıları ve çocuk yetiştirme tutumları ile çocuğun motor gelişimi arasındaki ilişkinin incelenmesi [Yayımlanmamış yüksek lisans tezi]. Haccetepe Üviversitesi Sağl1k Bilimleri Enstitüsü. https://doi.org/10.36731/cg.689288

Koç Akran, S., \& Bakır, B. (2019). Öğretmenlerin duygusal zekâlarıyla öz yeterlilikleri arasındaki ilişki. Uluslararası Hakemli Sosyal Bilimler E-Dergisi, 75, 157-173.

https://doi.org/10.17755/esosder.519230

Köksoy Mentiş, A. (2017). Sınıf öğretmeni adaylarının müzik öğretimi öz yeterlilik düzeylerinin incelenmesi (Niğde Ömer Halisdemir Üniversitesi örneği). Mehmet Akif Ersoy Üniversitesi Eğitim Fakültesi Dergisi, 44, 297-320. https://doi.org/10.21764/maeuefd.335473

Milli Eğitim Bakanlığı [MEB]. (2018). Müzik dersi öğretim programı (İlkokul ve ortaokul 1, 2, 3, 4, 5, 6, 7 ve 8. siniflar). MEB Yayınları. https://doi.org/10.32547/ataunigsed.463634

Özdamar, K. (2002). Paket programlarla istatistiksel veri analizi-1 (4. basım ). Kaan Kitapevi.

Saracaloğlu, A., Aldan Karademir, Ç., Dinçer, B., \& Dedebali, N. (2017). Öğretmenlerin öğretme stilleri, öz yeterlik ve iş doyumlarının belirlenmesi. E-Journal Of New World Sciences Academy, 12(1), 58-85. https://doi.org/10.12739/nwsa.2017.12.1.1c0669

Uçan, A., Yıldız, G., \& Bayraktar, E. (1999). İlköğretimde müzik öğretimi (İlköğretimde etkili öğretme ve öğrenme öğretmen el kitabı). Okan Matbaacılık.

Yaşar Ekici, F. (2017). Okul öncesi öğretmen adayları ile pedagojik formasyon eğitimi alan öğretmen adaylarının öğretmenliğe yönelik öz yeterlik inançlarının karşılaştırılması. İnsan ve Toplum Bilimleri Araştırmaları Dergisi, 6(5), 3003-3022. https://doi.org/10.20860/ijoses.334823 